\title{
THE EARLIEST CORRELATION OF CLINICAL AND \\ EXPERIMENTAL AURICULAR FIBRILLATION
}

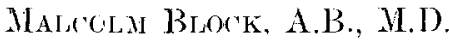 \\ AnN ARbor, Mich.
}

FIBRILllary activity of cardiac musele was first demonstrated by Hoffa and Ludwig, ${ }^{1}$ in $\mathbf{1 8 5 0}$, as a result of their attempt to produce tetanic contractions in the ventricles of various cold-blooded animals and mammals by direct faradization. The same phenomenon was produced by Einbrodt," in 1860, and later by Vulpian, ${ }^{3}$ who also observed that a similar, but generally more transient, condition could be produced in the auricle of the dog. However, the elinical occurrence and importance of auricular fibrillation were overlooked for at least twenty-five years, and the condition was regarded primarily as a laboratory curiosity, being frequently produced by direct faradization of the heart and the administration of various toxic and pharmacologic agents. It is true that irregularities of the pulse in man were observed and recorded by Marey ${ }^{4}$ as early as 1863, and later by Riegel," Sommerbrodt, ${ }^{6}$ Janowski, ${ }^{7}$ and numerous other clinicians. These irregularities were given a variety of names, such as the "mitral pulse," delirium cordis, pulsus irregularis perpetuus, and the absolutely irregular pulse. However, they were neither adequately recognized as definite clinical entities, nor correlated with those experimentally observed in animals, such as auricular fibrillation. Indeed, it was not until 1903 that Hering ${ }^{8}$ definitely established the fact that the absolutely irregular pulse is a definite clinical entity. With the introduction of the electrocardiograph, Lewis ${ }^{9}$ and Rothberger and Winterberg ${ }^{10}$ ultimately proved that the majority of these irregularities observed in man were one and the same, and were the clinical countcrpart of the experimental auricular fibrillation ohserved in animals.

The correlation between the clinical and laboratory observations was suggested, however, prior to the publication of the papers of Lewis and Rothberger and Winterberg. This earlier correlation was an outgrowth of the investigations of Arthur Cushny, undertaken while he was professor of Materia Medica and Therapenties in the Medical School of the University of Michigan, at Ann Arbor. Cushny ${ }^{11}$ states that he had been interested in cardiac inregularities as early as 1890. He was familiar with auricular fibrillation as produced in animals, hoth by direct faradization of the heart and by the administration of various drugs, such as digitalis, and he had frefuently observed the condition in his labora-

From the Department of Intemal Medicine. Tuiversity of Michigan Medical School, Ann Arbor.

Received for publication June 2, 1939. 
tory. This led him to wonder about the nature of the various pulse irregularities observed in man. In collaboration with George Jock, who was at that time professor of Medicine at Ann Arbor, he was able to study such irregularities in man by means of the dacquet sphygmochronograph. With this instrument he reeorded the radial pulse in patients with all of the types of irregularities of the heart which he had observed in his laboratory animals. In 1899 he published ${ }^{11}$ the results of this work, and in this paper he pointed out the similarity of the clinical sphygmogram in cases of delirium cordis and that obtained from dogs during auricular fibrillation, and suggested that the two conditions might be identical. Previous to this, no writer had even faintly hinted at such an idea, but, nevertheless, the suggestion was entirely overlooked at the time.

In 1906 , and again in 1907 , Cushny, ${ }^{12,13}$ in collaboration with Edmunds, published and compared pulse tracings from a patient with delirium cordis and those from dogs with experimentally produced auricular fibrillation. With these more complete data, the suggestion regarding the identity of the two conditions was reiterated. This suggestion was first recognized and discussed by Wenckebach, ${ }^{14}$ later by Lewis, ${ }^{9}$ and more recently by Garrey. ${ }^{15}$ In 1912, Lcwis ${ }^{16}$ pointed out that his remembrance of the original suggestion and paper by Cushny and Edmunds ${ }^{12}$ finally led him to compare more closely, and finally to correlate, the electrocardiograms from animals with auricular fibrillation with those obtained from patients with an absolutely irregular pulse. In general, however, more recent writers (e.g., White ${ }^{15}$ ) appear only vaguely aware of this contribution, and have given it scant notice. Because this was the first correlation of the laboratory and clinical observations, because the existence of this correlation is not more generally known, and, finally, because there is an important and historically interesting phase of this story that is entirely unknown, a presentation of the complete history of this contribution seems justified.

On Dec. 23, 1901, Mrs. H. H., a 64-ycar-old widow, entered the University Hospital, in Ann Arbor, complaining chiefly of an ovarian fibroid. She was sent to the Gynecology Service of Dr. Reuben Peterson and was successfully operated upon. At this time Dr. Charles Edmunds was an intern on this service, and during his routine examination of the patient he observed a paroxysmal irregularity of the pulse. He had been interested in cardiae irregularities and had previously discussed with Cushny the latter's observation, made in 1899. This interest led him to make tracings of this patient's radial pulse by means of the Jacquet sphygmograph. The resemblance of these tracings to those he had seen Cushny make on dogs with auricular fibrillation aroused his curiosity, and he had Cushny examine the patient. The original hospital records of this patient, which are reproduced here in part (Figs. 1, 2, and 3 ), substantiate these statements. Fig. 3 is a portion of the daily 
record of the patient, indicating the clinical observation of the paroxysmal irregularity of the pulse, and showing that the patient was examined by Cushny on Dec. 28,1901 , the day the pulse tracings were made. It is of interest to note the comment that the patient herself had noticed the irregularity previously. The pulso tracings that were made have been reproduced from the originals (Figs. 4 and 5 ). Cushny compared these tracings with those secured from dogs with aurieular fibrillation (Fig. 6). He believed that the striking resemblance constituted excellent evidence in favor of his original suggestion.

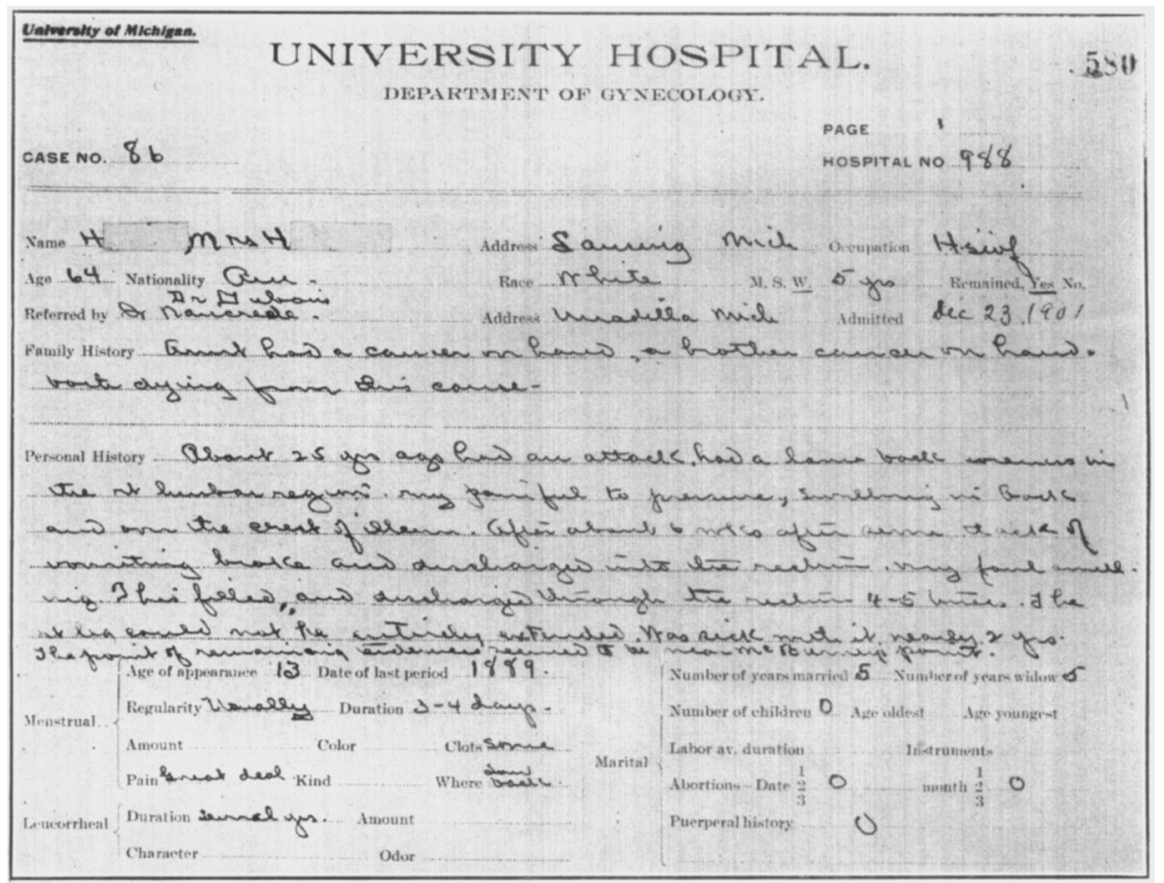

Fig. 1.-The first page of the original hospital record of Mrs. H. H., a 64-year-old widow, who entered the University Hospital Dec. 23, 1901.

On March 12, 1902, Edmunds presented this material at the regular meeting of the Ann Arbor Medical Club, and in his discussion of the paper Cushny reiterated his belief in the identity of the clinically observed arrhythmia and experimental auricular fibrillation. He pointed out that in both conditions (compare Figs. 4 or 5 and 6 ) there was not only an irregularity with respect to sequence of pulses, but also in their amplitude. Thus, for example, in the upper tracing of Fig. 5, if one considers the downstrokes after any of the first few smooth upstrokes, one sees many small pulses which are irregular in sequence and amplitude. A comparison with the upper tracing of Fig. 6, which was taken from a dog during experimental auricular fibrillation, shows the same thing. 


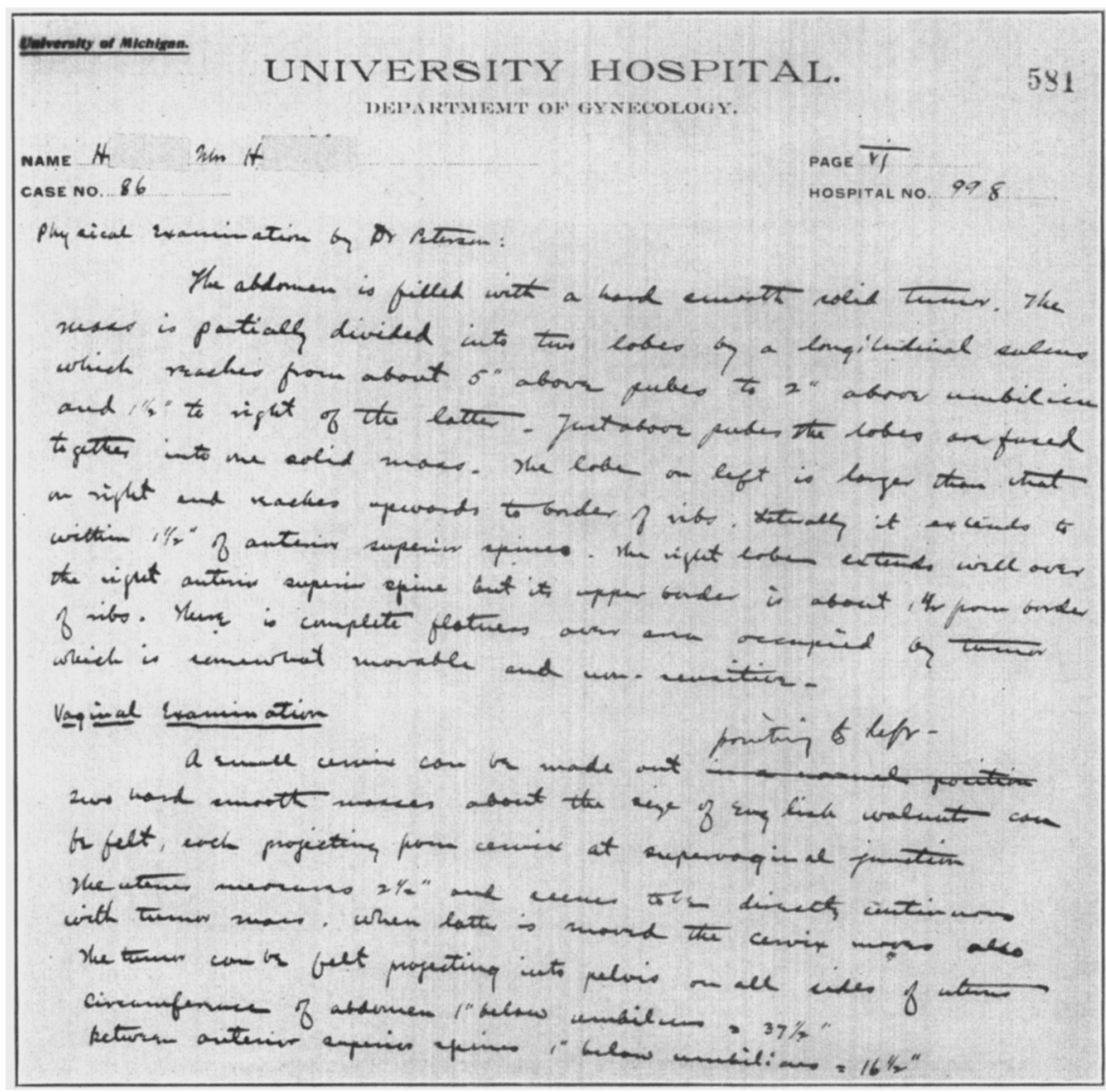

Fig. 2.-The second page of the hospital record of Mrs. H., showing the physical examination as recorded by Dr. Edmunds.

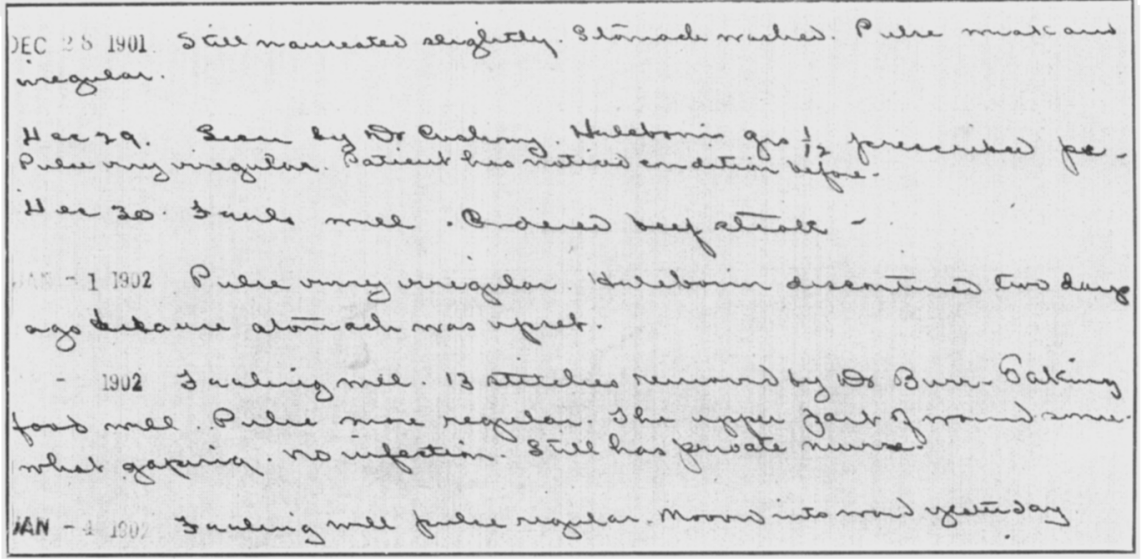

Fig. 3.-A portion of the daily progress notes kept on the patient. Note the examination by Dr. Cushny on December 29 . 
Infortunately, the observations presented to the Ann Arbor Medical (Yub received practically no notice. The proceedings of this organization were irregularly recorded in the Physician and Surgeon, a medical journal published in Ann Arbor for several years, but the proceedings of this particular meeting were omitted. The result was that the paper which was presented in 1902 remained buried in obscurity. However, it has been possible to locate the original records of the Ann Arbor Medical
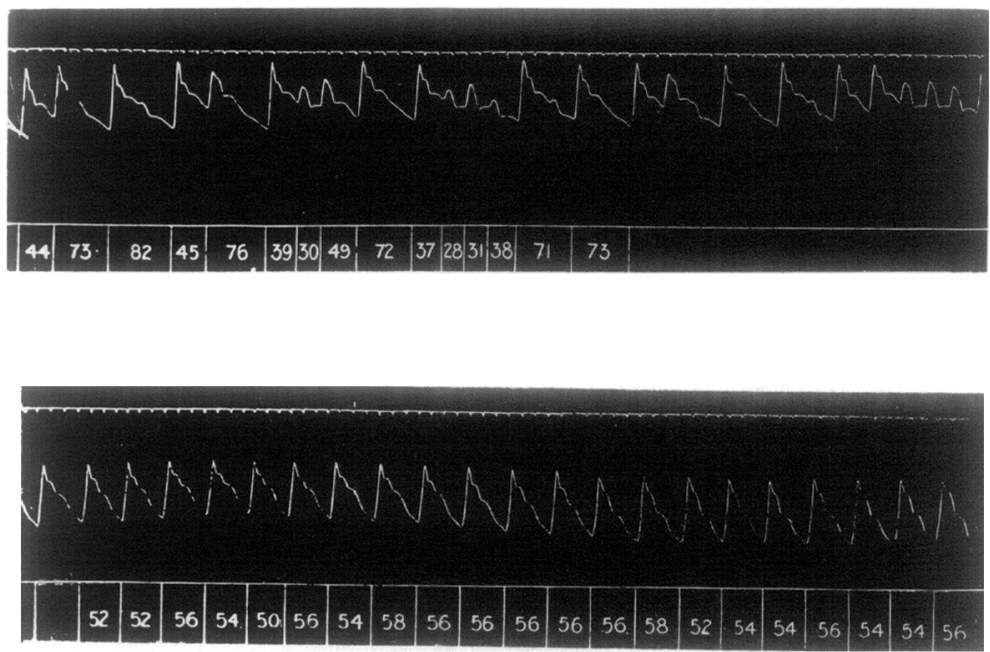

Fig. 4--Pulse tracings made by means of the Jacquet sphygmograph on December 28. Upper tracing was made at 1:45 P.M., lower tracing at $2: 45$ P.M.
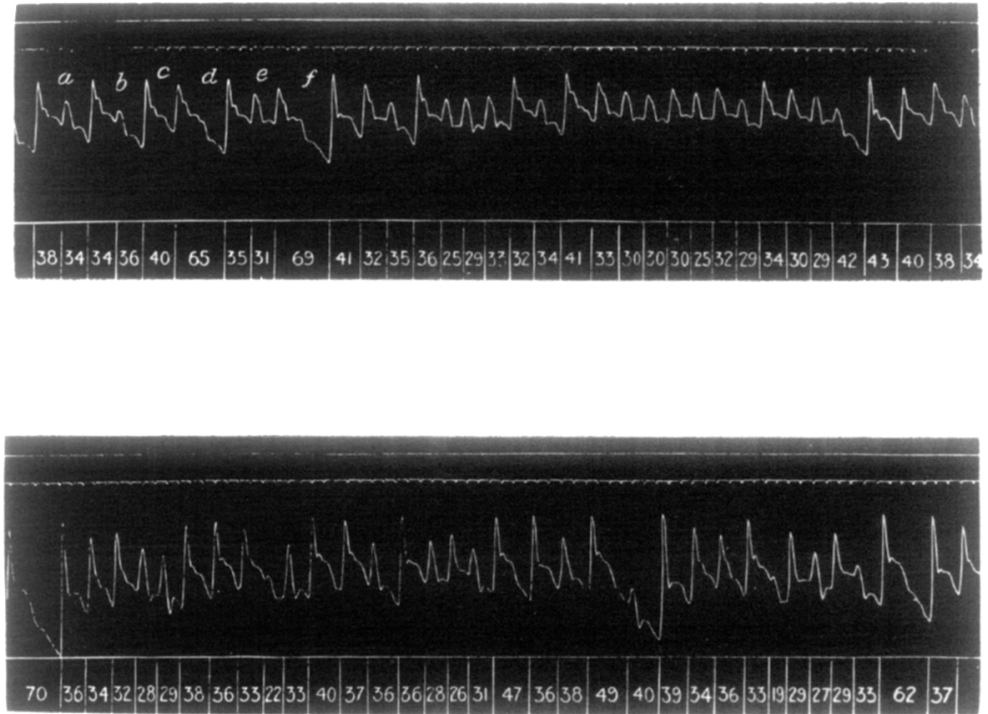

Fig. 5.-Further pulse tracings made on December 28. Upper tracing was made at $3: 45$ P.M., lower tracing at $4: 45$ P.M. 


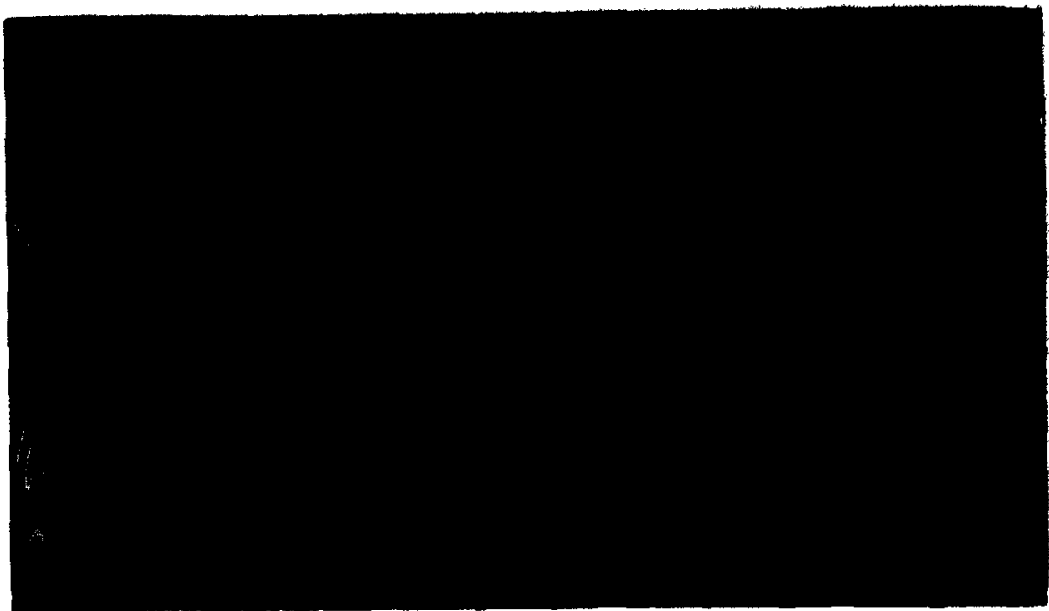

Fig. 6. - Tracings from earotid of dog made by means of Hürthle's tonometer. Uppermost tracing made during prolonged fibrillation. In midale tracing fibrillation was induced at $C$. In lowermost tracing there was imperfect fibrillation from $A$ to $B$, no fbrillation after $B$.

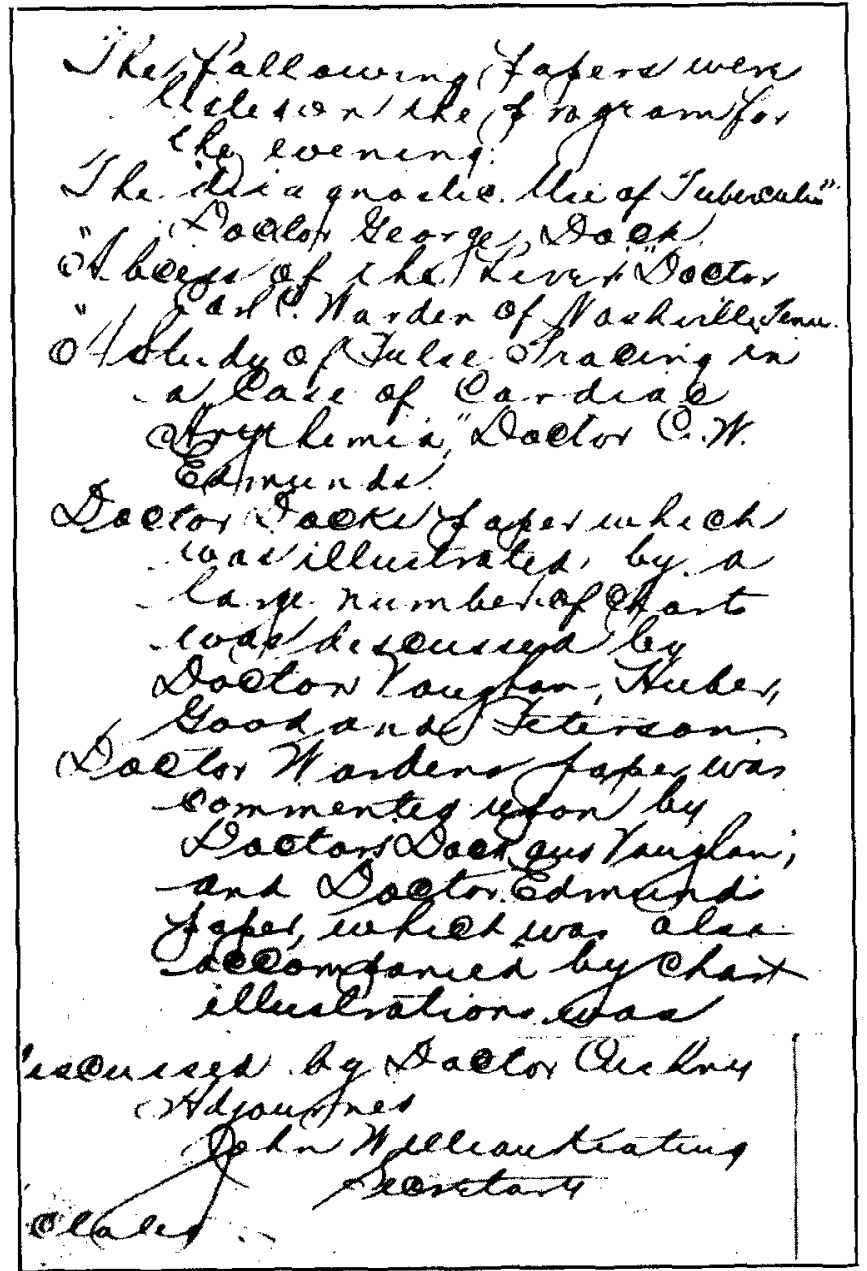

Fig. 7.-Page from record of Ann Arbor Medical Club, March 12, 1902, showing the papers given. Note the third paper reari, and the notation at the end regarding the discussion by Dr. Cushny. 
Club which were kept by the secretary. I portion is reproduced here (Fig. 7), and confirms the facts as given. Thus it will be seen (Fig. 7) that a meeting was held March 12, 1902, and that, in addition to several other papers, Dr. Charles Edmunds presented one, entitled "A Study of Pulse Tracings From a Case of Cardiac Arhythmia." In addition, the notation is made that Dr. Cushny discussed the paper and the accompanying pulse tracings that were presented. For a knowledge of what was said in the course of the diseussion the author is indebted to the excellent memory of Dr. Edmunds. In addition, we have the later statement of Cushny ${ }^{18}$ that he had reached the conclusions stated here as early as 1901 .

We thus have cvidence of the original and definite correlation of delirium cordis in man with experimental auricular fibrillation. It should be emphasized that this was accomplished seven years prior to the presentation of the final proof by Lewis and Rothberger and Winterberg that the two conditions are identical. The further history of this patient is of interest. As has been pointed ont, the case, including the pulse tracings and conclusions, was finally reported in 1906, and again in 1907 . The 1906 report ${ }^{12}$ was rather ohscure and passed unnoticed. Fox ${ }^{19}$ further studied and reviewed this case. The patient was scen oreasionally at the Tniversity Hospital for several years. When examined for the last time, in 1909. her cardiac irregularity had become permanent, and eventually she showed all the evidences of the cardiac failure which finally led to her death.

The author wishes to aknowledge gratefully the kind interest and valuable help of Dr. Arthur C. Curtis and Dr. Charles W. Edmunds in the preparation of this paper.

\section{REFEREYCES}

1. Hoffa, M., and Ludwig, E.: Einige nene Versuche über Herzbewegung. Ztsehr. f. rat. Med. 9: 107, 1850.

a. Einbrodt: Über Herzreizung und ihr Verhältniss zum Blutdruck. Sitzungsber. d. k. Akad. d. Wissenseh. Math.-naturw. Cl., Wien 38: 345, 1860.

3. Vulpian, A.: Sur les effets de la faradization des ventricules du coeur chez le chien. Compt. rend. Soc. de biol., 1: 6.s., 394, 1875; also, Gaz. méd. de Paris, 4, 4. s., 16, 1875 ; also, Arch. de physiol. norm. et path., Paris, 1, 2.s., 975, 1875 .

4. Marey, Étienne J.: Physiologie médicale de la circulation du sang, basée sur l'étude graphique des mouvements du coeur et du pouls artériel, avec application aux maladies de l'apparoil eirculatoire. P. 568, Paris, 1863, A. Delahaye.

5. Riegel, F.: Über Arhythmie des Herzens. Samml, klin. Vorträge (Volkmann), n.F., No. 227 (Inn. Med., 68), 1309, 1898.

6. Sommerbrodt, J.: Über Allorliythmie und Arhythmie des Herzens und deren Ursachen. Deutsches Arch. f. klin. Med. 19: 392, 1877.

7. Janowski, W.: Über die diagnostische und prognostische Bedeutung der exakten Pulsuntersuchung. Samml. klin. Vorträgc (Volkmann), n.F., No. 192 (Inn. Med., 57), 975, 1897.

8. Hering, H. E.: Analyse des Pulsus irregularis perpetuus. Prag. mer. Wehnschr. 28: 377,1903 .

9. Lewis, T.: Auricular Fibrillation: a Common Clinical Condition, Brit. M. I. 2: 1528, 1909; Heart 1: $306,1909-10$.

10. Rothberger, G., and Winterberg, A.: Vorhofflimmern und Arluythnia perpetua, Wien, klin. Wehnschr. 22: 839,1909 .

11. Cushny, A.: On the Interpretation of Pulse-Tracings, J. Exper. Merl. 4: 327, 1899 . 
12. Cushny, A., and Edmunds, C. W.: Paroxysmal Irregularity of the Heart and Auricular Fibrillation. Aberdeen University Studies (Bulloch) 21: 95, 1906. 13. Cushny, A. R., and Edmunds, C. W.: Paroxysmal Irregularity of the Heart and Auricular Fibrillation, Am. J. M. Sc. 133: 66, 1907.

14. Wenckebach, K. F.: Beiträge zur Kenntnis der mensehlichen Herztätigkeit. Arch. f. Anat. u. Physiol., Physiol. Abt. p. 1, 1907.

15. Garrey, W. E.: Auricular Fibrillation, Physiol. Rev. 4: 215, 1924.

16. Lewis, T.: A Lecture on the Fvidences of Auricular Fibrillation Treated Historically, Brit. M. J. 1: 57, 1912.

17. White, P. D.: Heart Disease, P. 744, New York, Ed. 2, 1937, The Macmillan Co.

18. Cuslumy, A. R.: Irregularities of the Heart and Auricular Fibrillation, Am. J. M. Se. 141: 826, 1911.

19. Fox, G. H.: The Clinical Significance of Transitory Delirium Cordis, Am. J. M. Sc. 140: 815,1910 . 